\title{
Discussion
}

The President said these contributions had proved to be extraordinarily interesting ones. Though practitioners in this special branch had not yet reached the Millennium in the matter of treating gonorrhoea, he thought they were now on the right lines, and as he had not much experience of gonorrhœa except in little girls, he would not offer remarks at the moment.

Dr. ANwYL-Davies thanked the authors for their excellent papers, and for the supporting diagrams, which gave a clear view of the treatment and the results. He had himself used this ecto-antigen in I927 which was also prepared by Dr. Oliver, treating in this way a small series of cases ; and he remembered two cases in particular in which the results were extraordinarily good. But in those two, instead of injecting the ecto-antigen into the groin above the glands it was injected, in one case, into the uterine cavity, while in the other it was injected into the cervical tissue. Those cases did better than did those in which the injection was made into axillæ and groins.

Dr. Oliver himself pointed out what was the great difficulty, namely, that at present one could not use the method as a routine, owing to the difficulties in preparing the material.

He asked whether Dr. Oliver knew, when he had prepared his ecto-antigen, whether it would act or not. One knew that in preparing ordinary gonococcal vaccine, even with the same strains, one might prepare a dozen bottles, only one of which would prove effective.

He understood that Dr. Hughes had performed the complement fixation tests, and Dr. Oliver said this test came down more rapidly after the ecto-antigen had been used than when normal methods of treatment were employed. He asked whether the usual method of com- 


\section{TREATMENT OF GONORRHEA}

plement fixation was used, or whether Dr. Price's more sensitive method of testing the complement fixation was employed. The latter was found to be so much more sensitive, that when the case was being cured the curve was longer, and the reaction came down more slowly, occupying a longer period in doing so.

This was an excellent piece of work, and he congratulated both the readers.

Dr. Hughes said he was unable to answer Dr. Anwyl Davies' question. He did not know the date on which the complement fixation was done. If it was before the beginning of November, it was by the comparatively insensitive method, but if since that date, it was by the more sensitive one. (Dr. DAvies : All were in the last year or so.)

General Henderson also added his congratulations to the readers of the papers.

He was in the Eastern Command when Major Dimond did his pioneer work, and many deplored that officer's loss from the service. In the Army, from the economic view-point alone, gonorrhœa was a matter of great importance and difficulty. He had recently returned from India, and there, in some cases, a cure was obtained in thirty-five days, but others took fifty-eight days or longer, and there were always a few cases in which the disease persisted for months. In fact, the time taken to cure gonorrhœa had not been materially reduced since he joined the service thirty-three years ago.

Now, while by suitable prophylaxis we had reduced, in a marked degree, the incidence of syphilis and soft chancre, we had failed to produce a reliable preventive of gonorrhœa, with the result that many working days were lost through this disease.

An important problem therefore arose as to what should be done with chronic cases? Should they be kept in hospital until all the criteria of cure were satisfied, or would it be safe to discharge them to duty while still carrying on treatment?

He was inclined to recommend discharge to duty, as he thought by that means their powers of resistance to the disease were more likely to be raised than by a prolonged stay in hospital, where they often seemed to go from bad to worse.

The papers read to-night gave one great hope that at 


\section{BRITISH JOURNAL OF VENEREAL DISEASES}

last, perhaps, we were on the track of a more reliable and, let us hope, a more rapid cure, and General Henderson wished both Dr. Clements and Dr. Oliver all success in their further investigations.

He suggested that in those cases which were slow or reluctant to produce the necessary anti-bodies some means might yet be discovered of stimulating their production. Was not the case in which, after a prolonged absence, anti-bodies suddenly appeared after an attack of salpingitis an example of such stimulation?

Dr. Osmond said he did not know whether it was Dr. Clements' experience, but it had always struck him, the speaker, that there were two very distinct classes of cases of gonorrhœa : those which reacted to this vaccine, and those which did not so react. These could be sharply demarcated. He was thinking of two cases in which the vaccine appeared to do more harm than good. He would like to know whether Dr. Clements had had the same experience, and how long he continued with the vaccine before giving it up. In his own practice, if after six weeks the patient was not getting better, he was inclined to drop the treatment. What ought one to do in cases of failure with the treatment?

Dr. Violet RUSSELL said she had the feeling that these papers marked an epoch-making discovery in the treatment of gonorrhœea. So far, practitioners in these subjects had felt fairly hopeless in the matter of prognosis, because some of the cases of gonorrhœa hung on so long. Now, however, she felt that treatment was being based on the right lines for securing a good cure, and that in the future one might be as hopeful as in cases of syphilis.

Colonel L. W. HARrison said he felt especial pleasure over the reception which had been accorded to these two papers, because he had been interested in the development of this work from the beginning. He had thought he might have to defend the title of the paper, as it referred to a " new" method of managing gonorrhœa, and it could be said that everybody had been using vaccines and the complement fixation, so that there was nothing especially new in its details except the particular method by which the vaccine had been made. But, in sum total, the method was new, and it marked a new and more precise method of managing cases of gonorrhœa. Hitherto in the case of gonorrhœa practitioners I68 


\section{TREATMENT OF GONORRHEA}

had been " wandering in the desert," treating empirically and trusting to impressions. Many people declared that vaccines were of no use for uncomplicated gonorrhœea, but that they did well in complicated cases. He, the speaker, had always felt that vaccines, if they were good antigens, were useful in all stages of the disease; it was a matter of getting a vaccine which had good antigenic properties. With regard to the question of the use of complement fixation in measuring the resistance of a patient with gonorrhœa, and the parallelism between the clinical improvement and the titre of the complement fixation reaction, that was not new : it was necessary to remind members that that was discovered by Thomson, in Rochester Row Hospital, during the war. When Thomson was first working at detoxicated vaccines, the effect of the vaccines was watched through the medium of the complement fixation reaction, as well as clinically, and it was frequently noted then that as the complement fixation reaction increased in titre, so the patient improved clinically. As an illustration : a patient had been in the Rochester Row Hospital a year. The complement fixation reaction was then, a year after infection, completely negative. The new vaccine was used, the complement fixation reaction became positive, and the patient lost his gonococci. The work at Rochester Row during the war and that forming the basis of the paper they had heard this evening showed that the complement fixation test could not be dispensed with in the management of gonorrhœa.

Whether this particular vaccine was the best or would be displaced by a better did not affect the principle at all : the main principle was to ensure good drainage and to watch the resistance by means of the complement fixation test. If it was found that the complement fixation reaction could not be pushed up by one method of therapy, another must be tried; if the progress of the case was watched in that way, treatment would be on far more precise lines than hitherto.

He thought General Henderson perhaps too pessimistic when he said that the stay in military hospitals on account of the disease was now as long as formerly. How about relapses? Were there now fewer relapses than before? (General HENDERSON : I agree that that is so, but still there are more relapses than one likes.) 


\section{BRITISH JOURNAL OF VENEREAL DISEASES}

As to whether subjects of gonorrhœa would be better out of the hospital than in, he had always thought that when military patients had passed the acute stage there seemed no reason why they should not be treated like civilians ; let them do their work, and attend periodically to have their treatment. (General Henderson: That is my view, too.) There were so many civilians abroad with gonorrhœea already that a few extra soldier patients out of hospital, though not yet completely cured, would not greatly influence the general incidence of gonorrhœa.

The PRESIDENT repeated his congratulations to the authors of these two papers, which certainly pointed to new criteria which would probably help in the successful treatment of the disease.

He asked whether the readers of the papers had tried the method for children. In children the duration of gonorrhœa varied enormously, in his experience ; sometimes a child could be cleared of its gonorrhœa in four to six weeks, but sometimes that took eight to ten or more months of continual treatment. He did not see why the method should not be used for children.

In the preparation of an antigen in the ordinary way one liked to get a recently isolated culture, which was usually of moderate or considerable virulence; but in this case it appeared that one continued to grow the organism until it became saprophytic, possibly avirulent. He would like to know whether it would be possible to standardise such an antigen, and, after preparation, to know how strong it was.

With regard to dosage, he asked whether I.5 c.c. (the maximum dose mentioned in the papers) was used intra-dermally, because that would be too large for a child. It was Bezredka who brought the intradermal method of injection to the notice of the profession, in the treatment of certain intestinal affections.

Mr. KING said he gathered that the use of the ectoantigen had been confined to the more chronic cases. To carry the matter to its logical conclusion it was desirable to try the effect of ecto-antigen in acute cases, but he did not gather that this had been done. The best opportunity of cutting short the infection was to introduce some such method of raising the titre of the complement fixation test before the natural resistance produced anti-bodies. Even by Price's later and more sensitive test 


\section{TREATMENT OF GONORRHCA}

it often took a fortnight for the fixation test to become positive in acute gonorrhœa. $\mathrm{He}$ asked, therefore, whether Dr. Clements had tried ecto-antigen in acute cases; and if so, did any complications arise during the negative phase?

Major DoBle said that when Dimond was first doing his work, two or three years before anything about it was published, he talked about " polar bodies," and he said, "I want you to try injections on any patient you think is cured, to see if a relapse occurs. He advocated giving an intradermal injection every day, starting with $\mathrm{O} \cdot \mathrm{I}$ of a c.c., injecting into the skin of the penis, then into the skin near the glands on each side of the groin, then into the skin round the axillæ: Dimond was very keen on the urine having a $p \mathrm{H}$ of from 7 to $7 \cdot 4$. Several patients had their gonorrhœa cleared up quickly by him, after either one or two injections. For the vaccine he first thought that it was very important to have the herring roes fresh; later on he used humid roes.

Dr. Clements, in reply, said that a short time ago he would have been inclined to have discharged such chronic cases from the Army, but, having recently been looking after a case of gonococcal ophthalmia, he would hesitate to turn such cases out of hospital unless he were sure that the patients were going immediately to seek medical advice elsewhere.

In a number of cases he had persisted with the vaccine for three or four months, but the majority of cases cleared up sooner. He had only treated one child with ectoantigen : a child two years old with gonococcal vulvovaginitis. When he started, the complement fixation was negative, and the ecto-antigen stimulated a slight reaction to \pm . The child cleared up well. It was difficult to get the complement fixation reaction positive in a child.

With regard to dosage, he did not mean that he gave all cases I. 5 c.c. ; a careful start was made with $0 \cdot$ I of a c.c. Some cases tolerated big doses without severe reaction.

$\mathrm{He}$ had treated some acute cases in this way; some of them did well, others not so well. The idea at the commencement of this investigation was to try this method of treatment on cases in which other methods had failed.

Dr. Oliver, in reply, said that the chief point raised in 


\section{BRITISH JOURNAL OF VENEREAL DISEASES}

the discussion concerning the actual vaccine was the question of its standardisation. The point there was that these protein bodies were difficult to estimate satisfactorily. Though he had tried various methods of precipitating them, the chief difficulty was that one used so much of one's vaccine in making an estimation as to leave one wondering whether it was worth all the trouble. $\mathrm{He}$ thought it sufficient if one was certain of the number of polar bodies in the smear preparations of the cultures and prepared the material in that way. For practical purposes it was near enough to compare batch with batch. He did animal experiments regarding activity, and these concerned the response in the general blood picture of the rabbit, the criterion being the smallest amount necessary to produce a definite response in the blood picture in respect of the large mono-nuclear cells. Experiments made in regard to spleenic injections made him think that the vaccine acted through the reticulo-endothelial system. 